\title{
Functional outcome and cost-effectiveness of pulsed electromagnetic fields in the treatment of acute scaphoid fractures: a cost-utility analysis
}

\author{
Pascal F W Hannemann ${ }^{1 *}$, Brigitte A B Essers ${ }^{2}$, Judith P M Schots ${ }^{1}$, Koen Dullaert ${ }^{1}$, Martijn Poeze ${ }^{1}$ and Peter R G Brink
}

\begin{abstract}
Background: Physical forces have been widely used to stimulate bone growth in fracture repair. Addition of bone growth stimulation to the conservative treatment regime is more costly than standard health care. However, it might lead to cost-savings due to a reduction of the total amount of working days lost. This economic evaluation was performed to assess the cost-effectiveness of Pulsed Electromagnetic Fields (PEMF) compared to standard health care in the treatment of acute scaphoid fractures.
\end{abstract}

Methods: An economic evaluation was carried out from a societal perspective, alongside a double-blind, randomized, placebo-controlled, multicenter trial involving five centres in the Netherlands. One hundred and two patients with a clinically and radiographically proven fracture of the scaphoid were included in the study and randomly allocated to either active bone growth stimulation or standard health care, using a placebo. All costs (medical costs and costs due to productivity loss) were measured during one year follow up. Functional outcome and general health related quality of life were assessed by the EuroQol-5D and PRWHE (patient rated wrist and hand evaluation) questionnaires. Utility scores were derived from the EuroQol-5D.

Results: The average total number of working days lost was lower in the active PEMF group (9.82 days) compared to the placebo group (12.91 days) $(p=0.651)$. Total medical costs of the intervention group ( $€ 1594)$ were significantly higher compared to the standard health care (€875). The total amount of mean QALY's (quality-adjusted life year) for the active PEMF group was 0.84 and 0.85 for the control group. The costeffectiveness plane shows that the majority of all cost-effectiveness ratios fall into the quadrant where PEMF is not only less effective in terms of QALY's but also more costly.

Conclusion: This study demonstrates that the desired effects in terms of cost-effectiveness are not met. When comparing the effects of PEMF to standard health care in terms of QALY's, PEMF cannot be considered a cost-effective treatment for acute fractures of the scaphoid bone.

Trial registration: Netherlands Trial Register (NTR): NTR2064

Keywords: Scaphoid, Pulsed electromagnetic fields, Acute fractures, Cost-effectiveness analysis, Cost-utility analysis, Functional outcome

\footnotetext{
* Correspondence: pfwhannemann@gmail.com

'Department of Surgery and Traumasurgery, Maastricht University Medical

Centre, PO Box 5800, 6202 AZ Maastricht, The Netherlands

Full list of author information is available at the end of the article
} 


\section{Background}

The scaphoid has an essential role in proper functionality of the wrist. Fractures of the scaphoid bone are the most common fracture of the carpus, counting for up to $90 \%$ of all carpal fractures and $2 \%-6 \%$ of all fractures in the Netherlands [1,2]. In Western countries the annual incidence rate of scaphoid fractures is estimated between 2.9 - 5 cases per 10.000 inhabitants [3-5]. Usually, scaphoid fractures are initially diagnosed on conventional radiographs. However, diagnosis of a scaphoid fracture can be challenging, since non- and minimally displaced fractures are often not apparent in first instance on radiographs. Timely diagnosis and accurate follow-up with the use of other diagnostic modalities, like CT-scanning, and appropriate immobilization can decrease the likelihood of occurrence of adverse outcomes like nonunion and early osteoarthritis [1,6-9]. Furthermore, delayed union leads to longer immobilization and prolonged functional deficit. Since mainly the young and working population is affected, prolonged cast immobilization leads to more working days lost with socio-economic consequences. A previous study showed that even uncomplicated healing leads to a mean total of 155 working days lost, increasing to 296 days in case of complicated healing, for instance because of nonunion [2].

Physical forces (low intensity pulsed ultrasound (LIPUS) or pulsed electromagnetic field (PEMF)) have been widely used to accelerate fracture repair in delayed union [10]. It is thought to reduce osteoclast resorption, to induce osteoid formation and to stimulate angiogenesis [11]. Evidence has accumulated over the past two decades that physical forces can also be used in the treatment of acute fractures, shortening time to union by $30 \%$ and reducing nonunion within 12 weeks of initiation of therapy by $71 \%$ [12-14].

Implementation of PEMF to the conservative treatment protocol of scaphoid fractures is more costly compared to standard care. However, it might lead to cost-savings due to a reduction of the total amount of working days lost. Therefore it is necessary to assess whether PEMF stimulation is a cost-effective treatment for acute scaphoid fractures.

This paper reports the results of our economic evaluation, performed alongside a large double-blind, randomized, placebo-controlled, multicenter trial in which the costs and effectiveness of PEMF are compared with standard care in conservatively treated acute fractures of the scaphoid bone.

\section{Methods}

We performed an economic evaluation alongside a double-blind, randomized, placebo-controlled, multicenter trial involving five centres in the Netherlands, to establish the cost-effectiveness of pulsed electromagnetic fields (PEMF) in the treatment of acute scaphoid fractures. The clinical and radiological outcomes of the trial have been reported in detail elsewhere [15].

For the economic evaluation we used data from our randomized controlled trial and focused on functional outcome, costs and cost-effectiveness. The time horizon was similar to the clinical study from the moment of inclusion until 12 months follow-up.

Approval was obtained from the coordinating ethics review committee (Independent Review Board Nijmegen, The Netherlands) and each participating centre (Maastricht University Medical Centre, Maastricht, The Netherlands; Rijnstate Hospital, Arnhem, The Netherlands; Canisius Wilhelmina Hospital, Nijmegen, The Netherlands; Isala Clinics, Zwolle, The Netherlands; Maasziekenhuis Pantein Hospital, Boxmeer, The Netherlands). Written informed consent for participation was obtained from every patient.

\section{Patients}

All patients $>=18$ years of age diagnosed between January $1^{\text {st }} 2010$ and December $31^{\text {st }} 2011$ with an acute, unilateral undisplaced fracture of the scaphoid types A1, A2, B1 or B2 according to the Herbert classification [16], were included in the trial. Exclusion criteria were: displaced scaphoid fractures, proximal pole scaphoid fractures (Herbert type B3), fracture dislocations of the carpus or comminuted scaphoid fractures (Herbert type B4 and B5 fractures), presentation > five days after injury, additional fractures of the wrist, carpal or metacarpal bones, a pre-existing impairment of wrist function, pregnancy and presence of a life-supporting implanted electronic device. All scaphoid fractures were diagnosed by a combination of physical examination and radiographic imaging (conventional scaphoid series and CT scan) at the time of trauma. All included fractures were classified according to a CT-based modified Herbert classification [17]. All fractures were treated conservatively with immobilization in a below elbow cast with the first metacarpal and proximal phalanx immobilized. Electromagnetic stimulation was administered continuously for 24 hours a day using a PEMF bone growth stimulator incorporated into the cast (Orthopulse $\mathrm{III}^{\circ}$ PEMF bone growth stimulator, Ossatec ${ }^{\circ}$, Uden, The Netherlands). The signal characteristics of the PEMF device used in our study were: pulse amplitude $50 \mathrm{mV}$, pulse width $5 \mu \mathrm{s}$, burst width $5 \mathrm{~ms}$, burst refractory period $62 \mathrm{~ms}$, repetition rate $15 \mathrm{~Hz}$. Half of the PEMFdevices were randomly disabled in the factory. Identical devices and the same follow-up protocol were used for both control and PEMF cases. Neither the investigators nor the patients were aware of the device's functionality.

The PEMF device was removed six weeks after the start of treatment. The patients underwent clinical and 
Table 1 Costs per unit [21]

\begin{tabular}{lll}
\hline Unit & $\begin{array}{l}\text { Cost price in } \\
\text { academic } \text { hospital* }\end{array}$ & $\begin{array}{l}\text { Cost price in } \\
\text { general hospital* }\end{array}$ \\
\hline PEMF device & 665.90 & 665.90 \\
Application of a cast & 31.25 & 31.25 \\
Removal of a cast & 8.71 & 8.71 \\
$\begin{array}{l}\text { Wrist/scaphoid } \\
\text { conventional radiographs }\end{array}$ & 39.97 & 24.46 \\
$\begin{array}{l}\text { Wrist/scaphoid CT scan } \\
\text { Emergency department }\end{array}$ & 126.29 & 80.59 \\
visit & 154.45 & 154.45 \\
Outpatient clinic visit & 70.06 & 65.46 \\
\hline
\end{tabular}

${ }^{*}$ Costs are indexed to 2011 and given in Euro.

radiological examination (including multiplanar reconstructed CT scans) at 6, 9, 12, 24 and 52 weeks after the start of treatment. In patients with complete clinical and radiological union, the cast was removed at six, 9 or 12 weeks, depending on the time of union.

We hypothesized that PEMF would reduce the time to union by up to $30 \%$ with subsequent shortening of time off work [13]. Based on this information we conducted a power analysis with a two-sided significance level (alpha, type I error) of 0.05 and an assumed power (1-beta) of
0.8. This resulted in a total study group of 100 patients, with a sample size of 50 patients per group [18].

\section{Functional and quality of life outcomes}

All patients were required to fill in three questionnaires at baseline, 6, 9, 12, 24 and 52 weeks after the scaphoid fracture was diagnosed. The Patient Rated Wrist/Hand Evaluation (PRWHE) was used to assess the level of fracture related functional deficit and pain level from the patient's perspective. The PRWHE is a 15 -item questionnaire that allows patients to rate the level of wrist pain and disability in activities of daily living via a 10-point categorical scale from 0 (no pain/difficulty) to 10 (worst pain ever/unable to do) [19]. The EuroQol-5-D questionnaire was used for quality of life assessment through measurement of the following six dimensions: mobility, self-care, usual activities, pain/discomfort, anxiety/ depression and the visual analogue scale (VAS) [20].

\section{Costs}

Costs were collected from the first outpatient visit until 12 months follow up and included all costs in- and outside health care. Cost analysis within health care included costs of the intervention (i.e. device, application and removal of a plaster cast), wrist/scaphoid X-rays, wrist/ scaphoid CT-scans, emergency visits and outpatient

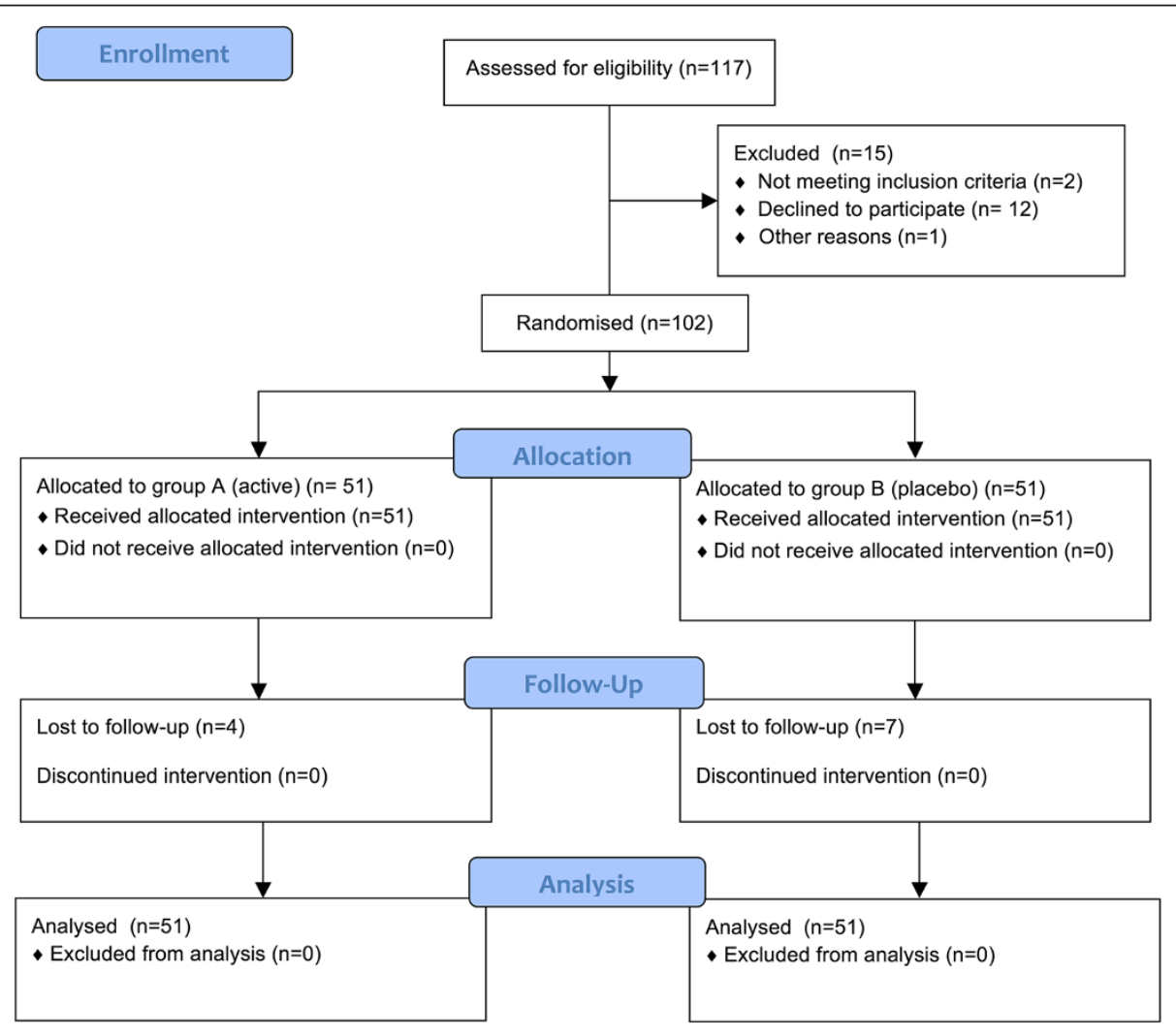

Figure 1 Consort flow diagram. 
clinic visits. Real resource use was collected from hospital information systems of the different hospitals. The costs per unit were derived from the financial department of our hospital and the Dutch guidelines for cost-calculations in health care [21]. Diagnostic tests (conventional radiographs and CT-scans) and outpatient clinic visits are more costly in university hospitals; therefore university and general hospital prices were used separately.

Costs concerning outside health care included productivity costs, as measured by the number of working days lost determined at baseline and 12, 24 and 52 weeks after inclusion, by the PRODISQ-questionnaire (PROductivity and DISease Questionnaire) [22]. The costs of productivity loss were calculated by means of the friction cost method, based on the average standardized wages per hour [21]. The basic idea of the friction cost method is that the amount of production lost due to disease depends on the time-span organizations need to restore the production at the initial production level [23].

No discounting was applied, since all data with regard to the costs and effectiveness were collected within one year. All costs are indexed to 2011. Table 1 provides an overview of the costs per unit.

Table 2 Baseline characteristics of the patients

\begin{tabular}{lll}
\hline Variable & $\begin{array}{l}\text { Group A } \\
\text { (Active PEMF) }\end{array}$ & $\begin{array}{l}\text { Group B } \\
\text { (Placebo) }\end{array}$ \\
\hline Number & 51 & 51 \\
Age - year* & $35(18-70)$ & $34(18-77)$ \\
$\begin{array}{l}\text { Days between fracture and start of } \\
\text { treatment* }\end{array}$ & $4.25(0-5)$ & $3.69(0-5)$ \\
Male (n, \%) & $40(78)$ & $38(75)$ \\
Fracture in dominant hand (n,\%) & $28(55)$ & $29(57)$ \\
Anatomical snuff box tenderness & $46(90)$ & $49(96)$ \\
(n, \%) & & \\
Pain with longitudinal compression & $39(77)$ & $45(88)$ \\
(n, \%) & & \\
Fracture type [17] (n, \%) & & $9(18)$ \\
- Tubercle (A1) & $9(18)$ & $20(39)$ \\
- Transverse waist, undisplaced (A2) & $19(37)$ & $18(35)$ \\
- Oblique (B1) & $15(29)$ & $4(8)$ \\
- Transverse waist with distraction (B2) & $8(16)$ & $11(22)$ \\
Comorbidities (n, \%) & & $38(75)$ \\
- None & $34(67)$ & $0(0)$ \\
- Osteoporosis & $0(0)$ & $1(2)$ \\
- Corticosteroids & $0(0)$ & $1(2)$ \\
- Multiple & $16(31)$ & \\
Smoking (n, \%) & & \\
\hline
\end{tabular}

*Variables are denoted as mean (range).

No significant differences were seen between groups.

\section{Economic evaluation}

The economic evaluation was performed from a societal perspective and includes a cost-utility analysis. The incremental costs per QALY (quality-adjusted life year), usually interpreted as the additional costs of PEMF to gain one additional QALY compared to standard care, were calculated. A QALY is calculated by multiplying the utility of being in a certain health state by the time a patient experiences that health state. Utility scores were derived from the EuroQol-5D and converted to utility scores by the UK Dolan algorithm [24].

\section{Statistical methods}

Statistical analysis was performed using proprietary statistical software with advanced statistics add-on modules (SPSS statistical package version 20.0; SPSS inc, $233 \mathrm{~S}$ Wacker Drive, Chicago, 60606 Illinois, United States). A statistician blinded from treatment allocation was recruited for analysis of the clinical data. P-values $<0.05$

Table 3 Assessment of functional outcome according to the Patient-Rated Hand/Wrist Evaluation (PRWHE)

\begin{tabular}{|c|c|c|c|}
\hline Variable & Group A (Active) & Group B (Placebo) & p-valu \\
\hline \multicolumn{4}{|c|}{$\begin{array}{l}\text { Pain Subscale* } \\
\text { (mean, }\left[95 \% \mathrm{Cl}^{* *}\right] \text { ) }\end{array}$} \\
\hline - Baseline & $25.7[21.4 ; 30.0]$ & $26.8[22.7 ; 31.0]$ & 0.708 \\
\hline - 6 weeks & $16.0[12.4 ; 19.5]$ & $15.4[11.3 ; 19.4]$ & 0.824 \\
\hline - 9 weeks & $14.6[11.1 ; 18.0]$ & $15.4[11.1 ; 19.6]$ & 0.770 \\
\hline - 12 weeks & $10.7[7.4 ; 14.0]$ & $10.2[6.6 ; 13.9]$ & 0.851 \\
\hline - 24 weeks & $8.3[4.9 ; 11.7]$ & $7.2[4.3 ; 10.1]$ & 0.631 \\
\hline - 52 weeks & $4.6[2.1 ; 7.1]$ & $3.7[1.1 ; 6.3]$ & 0.626 \\
\hline \multicolumn{4}{|c|}{$\begin{array}{l}\text { Function Subscale }{ }^{\dagger} \\
\text { (mean, }\left[95 \% \mathrm{Cl}^{* *}\right] \text { ) }\end{array}$} \\
\hline - Baseline & $74.3[67.9 ; 81.0]$ & $68.1[59.8 ; 76.3]$ & 0.235 \\
\hline - 6 weeks & $52.2[44.3 ; 60.1]$ & $47.5[38.4 ; 56.5]$ & 0.426 \\
\hline - 9 weeks & $29.3[21.0 ; 37.6]$ & $34.9[23.5 ; 46.3]$ & 0.411 \\
\hline - 12 weeks & $16.6[9.3 ; 23.9]$ & $20.8[12.2 ; 29.3]$ & 0.456 \\
\hline - 24 weeks & $8.1[4.0 ; 12.1]$ & $6.4[2.1 ; 10.7]$ & 0.569 \\
\hline - 52 weeks & $2.8[0.8 ; 4.7]$ & $3.4[0.5 ; 6.2]$ & 0.724 \\
\hline \multicolumn{4}{|c|}{$\begin{array}{l}\text { Total Score } \\
\text { (mean, }\left[95 \% \mathrm{Cl}^{* *}\right] \text { ) }\end{array}$} \\
\hline - Baseline & $62.9[56.5 ; 69.3]$ & $60.9[53.1 ; 68.7]$ & 0.687 \\
\hline - 6 weeks & $42.1[35.5 ; 48.7]$ & $39.1[31.0 ; 47.2]$ & 0.565 \\
\hline - 9 weeks & $29.2[22.1 ; 36.4]$ & $32.8[23.4 ; 42.2]$ & 0.531 \\
\hline - 12 weeks & $19.0[12.6 ; 25.4]$ & $20.6[13.2 ; 28.0]$ & 0.738 \\
\hline - 24 weeks & $12.3[7.1 ; 17.6]$ & $10.4[5.7 ; 15.1]$ & 0.586 \\
\hline - 52 weeks & $5.9[2.7 ; 9.2]$ & $5.4[1.5 ; 9.3]$ & 0.832 \\
\hline
\end{tabular}

*Best possible outcome (no pain) $=0$, worst possible outcome $=50$.

${ }^{* *} \mathrm{Cl}$, confidence interval.

${ }^{\dagger}$ Best possible outcome (no functional disability) $=0$, worst

possible outcome $=100$.

$\neq$ \#est possible outcome (no pain \& no functional disability) $=0$, worst possible outcome $=100$. 
Table 4 Assessment of functional outcome according to the EuroQoL-5D

\begin{tabular}{|c|c|c|c|}
\hline Variable & $\begin{array}{l}\text { Group A } \\
\text { (Active) }\end{array}$ & $\begin{array}{l}\text { Group B } \\
\text { (Placebo) }\end{array}$ & $p$-value \\
\hline \multicolumn{4}{|c|}{ Mobility* (mean rank**) } \\
\hline - Baseline & 49.35 & 43.52 & 0.052 \\
\hline - 6 weeks & 43.28 & 39.54 & 0.115 \\
\hline - 9 weeks & 39.19 & 38.76 & 0.848 \\
\hline - 12 weeks & 38.00 & 37.00 & 0.646 \\
\hline - 24 weeks & 37.54 & 36.54 & 0.597 \\
\hline - 52 weeks & 36.34 & 34.50 & 0.191 \\
\hline \multicolumn{4}{|c|}{$\begin{array}{l}\text { Self-Care* (mean } \\
\text { rank**) }^{* *}\end{array}$} \\
\hline - Baseline & 51.34 & 41.44 & 0.039 \\
\hline - 6 weeks & 44.51 & 37.22 & 0.111 \\
\hline - 9 weeks & 37.24 & 41.22 & 0.340 \\
\hline - 12 weeks & 37.42 & 37.58 & 0.960 \\
\hline - 24 weeks & 37.00 & 37.00 & 1.00 \\
\hline - 52 weeks & 35.29 & 35.00 & 0.359 \\
\hline \multicolumn{4}{|c|}{$\begin{array}{l}\text { Usual activities* } \\
\text { (mean rank**) }\end{array}$} \\
\hline - Baseline & 48.6 & 44.3 & 0.373 \\
\hline - 6 weeks & 42.3 & 40.6 & 0.704 \\
\hline - 9 weeks & 38.9 & 39.2 & 0.945 \\
\hline-12 weeks & 35.9 & 39.1 & 0.441 \\
\hline - 24 weeks & 38.4 & 35.5 & 0.309 \\
\hline - 52 weeks & 37.0 & 33.7 & 0.215 \\
\hline \multicolumn{4}{|c|}{$\begin{array}{l}\text { Pain/discomfort* } \\
\left(\text { mean } \operatorname{rank}^{* *}\right)\end{array}$} \\
\hline - Baseline & 49.3 & 43.6 & 0.250 \\
\hline - 6 weeks & 44.3 & 38.4 & 0.195 \\
\hline - 9 weeks & 39.1 & 37.8 & 0.769 \\
\hline - 12 weeks & 39.4 & 35.7 & 0.379 \\
\hline - 24 weeks & 40.7 & 33.2 & 0.051 \\
\hline - 52 weeks & 37.3 & 33.4 & 0.234 \\
\hline \multicolumn{4}{|c|}{$\begin{array}{l}\text { Anxiety/depression* } \\
(\text { mean rank**) }\end{array}$} \\
\hline - Baseline & 47.8 & 45.1 & 0.339 \\
\hline - 6 weeks & 40.9 & 42.2 & 0.625 \\
\hline - 9 weeks & 37.8 & 40.5 & 0.251 \\
\hline - 12 weeks & 35.5 & 39.5 & 0.091 \\
\hline - 24 weeks & 35.0 & 39.1 & 0.038 \\
\hline - 52 weeks & 34.4 & 36.8 & 0.229 \\
\hline \multicolumn{4}{|c|}{$\begin{array}{l}\text { VAS-score } \\
\left.\text { (mean, }\left[95 \% \mathrm{Cl}^{\dagger}\right]\right)\end{array}$} \\
\hline - Baseline & $72.5[65.9 ; 79.0]$ & $78.7[73.9 ; 83.4]$ & 0.126 \\
\hline - 6 weeks & $78.0[73.8 ; 82.3]$ & $82.6[78.4 ; 86.8]$ & 0.127 \\
\hline - 9 weeks & $82.2[78.3 ; 86.1]$ & $82.2[77.2 ; 87.3]$ & 0.987 \\
\hline
\end{tabular}

Table 4 Assessment of functional outcome according to the EuroQoL-5D (Continued)

\begin{tabular}{|c|c|c|c|}
\hline - 12 weeks & $84.8[80.7 ; 89.0]$ & $82.9[77.6 ; 88.3]$ & 0.576 \\
\hline - 24 weeks & 88.1 [83.9; 92.2] & 88.7 [85.0; 92.4] & 0.818 \\
\hline - 52 weeks & 87.9 [84.1; 91.8] & 90.8 [87.0; 94.7] & 0.282 \\
\hline \multicolumn{4}{|c|}{$\begin{array}{l}\text { *Mann Whitney } U \text { test; } \mathrm{p}<0.05 \text {. } \\
{ }^{* *} \text { Scores are presented as mean rank. The higher the score, the more } \\
\text { problems experienced with activities of daily living. } \\
{ }^{\dagger} \text { All variables are denoted as a score between } 0-100 \text {, with } 100 \text { being the best } \\
\text { possible outcome. } \\
{ }^{\ddagger} \mathrm{Cl} \text {, confidence interval. }\end{array}$} \\
\hline
\end{tabular}

were considered to indicate statistical significance. In case of normal distribution an independent student's $t$ test was performed, to compare means between the intervention and control group. The non-parametric Mann-Whitney $U$-test was used in case of ordinal variables and in cases where normality could not be assumed.

In case of missing values, a multiple imputation model was used to analyze and complete the dataset. Missing values were below $30 \%$ for all variables. Multiple imputations for missing values concerning the questionnaires were performed using all baseline characteristics (age, sex, type of fracture, hand dominance and comorbidity) and existing variables of the EuroQol-5D and PRWHE. For each missing value, 5 imputations according to the Bayesian probability rules were performed. In addition, multiple imputations were performed for missing data on the productivity loss, again using all baseline characteristics as stated above.

Since cost data generally have a highly skewed distribution, we performed a non-parametric bootstrap analysis (1000 replications) to estimate uncertainty intervals around the difference in mean costs and to quantify the uncertainty surrounding the incremental costeffectiveness ratio (ICER) $[25,26]$. The bootstrap analysis was performed in Microsoft Excel. Results of the bootstrap analysis regarding the effectiveness and costs were presented in a cost-effectiveness plane and an acceptability curve. The cost-effectiveness plane is a graphical presentation of four quadrants in which the additional costs and QALY's of a new therapy (active PEMF) are compared to standard care. The cost-effectiveness acceptability curve shows the probability of PEMF being more cost-effective compared to standard care. All patients were analyzed according to the intention-to-treat principle.

\section{Results}

Patients

A total of 117 patients were eligible for inclusion; 12 patients withdrew, for two patients a primary indication for operation was set and one patient was not mentally fit enough to participate in the study. Therefore, 102 
patients with clinical and radiographic diagnosis of a scaphoid fracture were included in the study and randomly allocated to either active PEMF treatment $(\mathrm{n}=$ $51)$ or placebo treatment $(\mathrm{n}=51)$ (Figure 1). The two groups were similar concerning baseline characteristics (Table 2).

\section{Clinical effect}

Results from our recently published clinical study showed no overall positive effect of adding PEMF to the conservative treatment of acute scaphoid fractures [15]. However, the use of PEMF in A2 type scaphoid fractures revealed a significantly shorter time to union [15]. Therefore, PEMF might accelerate union in a well-defined subgroup of stable, undisplaced scaphoid waist fractures.

For the PRWHE no significant differences were found between the active PEMF group and the control group at any of the time points (Table 3). Concerning Self-Care and Anxiety/Depression, both variables of the EuroQol$5 \mathrm{D}$, we found a significant difference at respectively baseline and 24 weeks. For the other variables of the EuroQol-5D there were no significant differences at any of the time points (Table 4).

\section{Costs}

The mean total health care costs per patient were $€ 875$ in the placebo group and $€ 1594$ in the active PEMF group (Table 5). This difference in costs was statistically significant $(€ 719,95 \%$ CI $€ 652$ to $€ 772)$ (Table 6) and could be attributed entirely to the use of the PEMF device.

Concerning productivity loss the average total number of working days lost was lower in the active PEMF group

Table 5 Resource use and costs per treatment arm

\begin{tabular}{|c|c|c|c|c|}
\hline \multirow[t]{2}{*}{ Unit } & \multicolumn{2}{|c|}{$\begin{array}{l}\text { Group A } \\
\text { (active PEMF) }\end{array}$} & \multicolumn{2}{|c|}{ Group B (Placebo) } \\
\hline & $\begin{array}{l}\text { Mean } \\
\text { total use } \\
\text { (n) }\end{array}$ & $\begin{array}{l}\text { Mean } \\
\text { total } \\
\text { costs* }\end{array}$ & $\begin{array}{l}\text { Mean } \\
\text { total use } \\
\text { (n) }\end{array}$ & $\begin{array}{l}\text { Mean } \\
\text { total } \\
\text { costs* }\end{array}$ \\
\hline PEMF device & 1.0 & 665.90 & 0 & 0 \\
\hline Application of a cast & 2.61 & 81.50 & 2.53 & 79.04 \\
\hline Removal of a cast & 2.61 & 22.71 & 2.53 & 22.03 \\
\hline $\begin{array}{l}\text { Wrist / scaphoid } \\
\text { conventional } \\
\text { radiographs }\end{array}$ & 1.0 & 30.85 & 1.0 & 31.15 \\
\hline $\begin{array}{l}\text { Wrist / scaphoid CT } \\
\text { scan }\end{array}$ & 2.95 & 276.78 & 2.65 & 255.35 \\
\hline $\begin{array}{l}\text { Emergency } \\
\text { department visit }\end{array}$ & 1.0 & 154.45 & 1.0 & 154.45 \\
\hline Outpatient clinic visit & 5.12 & 345.46 & 4.69 & 317.23 \\
\hline $\begin{array}{l}\text { Total health care } \\
\text { costs*** }\end{array}$ & & $€ 1594$ & & $€ 875$ \\
\hline
\end{tabular}

${ }^{*}$ Costs are indexed to 2011 and denoted in Euro.

**Total health care costs do not exactly add up due to the bootstrap analysis.
Table 6 Total costs per treatment arm

\begin{tabular}{llll}
\hline & $\begin{array}{l}\text { Group A (Active } \\
\text { PEMF) mean }\end{array}$ & $\begin{array}{l}\text { Group B } \\
\text { (Placebo) } \\
\text { mean }\end{array}$ & $\begin{array}{l}\text { Difference in } \\
\text { costs [95\% CI] }\end{array}$ \\
\hline $\begin{array}{l}\text { Total health } \\
\text { care costs* }\end{array}$ & $€ 1594$ & $€ 875$ & $€ 719[652 ; 772]$ \\
$\begin{array}{l}\text { Costs of } \\
\text { productivity }\end{array}$ & $€ 1226$ & $€ 1423$ & $€-197[-1158 ;$ \\
$\begin{array}{l}\text { los } \\
\begin{array}{l}\text { Total societal } \\
\text { costs*** }\end{array}\end{array}$ & $€ 2827$ & $€ 2253$ & $657]$ \\
\hline
\end{tabular}

*Costs are denoted in Euro.

${ }^{*} \mathrm{Cl}$, confidence interval.

***Numbers do not exactly add up due to the bootstrap analysis

(9.82 days) compared to the placebo group (12.91 days). However, this difference was not statistically significant $(\mathrm{p}=0.651)$. When including costs due to productivity loss in the cost-analysis, mean total costs for the active PEMF group are higher (€2827) compared to mean total costs for the standard treatment (€2253), although this difference is not statistically significant (difference $=€ 574$, 95\% CI $=€-423$ to $€ 1438$ ) (Table 6).

When excluding patients from the analysis that were student or unemployed (17 in the active PEMF group and 12 in the placebo group, $\mathrm{p}=0.27$ ), mean total costs for the active PEMF group are still higher $(€ 3305)$ compared to mean total costs for the standard treatment $(€ 2634)$ (difference $=€ 670,95 \% \mathrm{CI}=€-405$ to $€ 1732$ ) (Table 7).

\section{Cost-effectiveness}

The mean QALY was 0.84 for the active PEMF group and 0.85 for the control group, resulting in a nonsignificant difference of $0.01 \quad(95 \% \quad \mathrm{CI}=-0.01 ; 0.04)$ (Table 8 ). The cost-effectiveness plane (Figure 2) shows that the majority of all cost-effectiveness ratios (85\%) fall into the north-western quadrant where PEMF is less effective in terms of QALY's and more costly. When only considering patients with a paid job, the difference in QALY's was in favour of the PEMF group (non-

Table 7 Total costs per treatment arm for working patients only

\begin{tabular}{|c|c|c|c|}
\hline & $\begin{array}{l}\text { Group A (Active } \\
\text { PEMF) mean }\end{array}$ & $\begin{array}{l}\text { Group B } \\
\text { (Placebo) } \\
\text { mean }\end{array}$ & $\begin{array}{l}\text { Difference in } \\
\text { costs }[95 \% \mathrm{Cl}]\end{array}$ \\
\hline $\begin{array}{l}\text { Total health } \\
\text { care costs* }\end{array}$ & $€ 1543$ & $€ 840$ & $€ 703[637 ; 755]$ \\
\hline $\begin{array}{l}\text { Costs of } \\
\text { productivity } \\
\text { los }\end{array}$ & $€ 1747$ & $€ 1798$ & $€-51 \quad[-1119 ; 975]$ \\
\hline $\begin{array}{l}\text { Total societal } \\
\text { costs }^{* * *}\end{array}$ & $€ 3305$ & $€ 2634$ & $€ 670[-405 ; 1732]$ \\
\hline
\end{tabular}


Table 8 Incremental cost-effectiveness ratio of PEMF vs. standard treatment for acute scaphoid fractures

\begin{tabular}{llll}
\hline & Costs* $^{*}$ & QALY & ICER \\
\hline Group A (Active) & $€ 2827$ & 0.84 & \\
Group B (Placebo) & $€ 2253$ & 0.8545 & \\
Increment & $€ 574$ & -0.0145 & inferior
\end{tabular}

${ }^{*}$ Costs are denoted in Euro.

QALY, quality adjusted life year; ICER, incremental cost-effectiveness ratio.

significant difference: $0.01: 95 \% \mathrm{CI}=-0.04 ; 0.02)$ which results in an incremental cost-effectiveness ratio of $€ 113559$ per QALY gained which is unlikely to be considered cost-effective (Table 9). In addition, the costeffectiveness plane shows that although $64 \%$ of the costeffectiveness pairs are located in the north-eastern quadrant where active PEMF treatment leads to more effect against more costs, $29 \%$ is situated in the quadrant where PEMF is less effective and more costly (Figure 3) The acceptability curve (Figure 4 ) shows that even for a threshold up to $€ 70000$, there is only a $40 \%$ probability that PEMF is more cost-effective compared to standard care.

\section{Discussion}

Data about the amount of working days lost due to scaphoid fractures is limited. The most detailed source is a previously published prospective study that assessed, among other things, time off work due to carpal injuries in the Netherlands in the period from 1990 to 1993 [2]. In this study the mean total time off work for conservatively treated fractures of the scaphoid was 144 days with a range of 12 to 1353 days. In our trial the mean total number of working days lost was remarkably lower, 9.82 working days in the active PEMF group compared to 12.91 working days lost in the control group with a range of 0 to 190 days.
In the study by van der Molen et al. [2] the majority of the included patients (94\%) performed manual work whereby they needed both hands for their job. Only $2 \%$ of the study population was able to resume their previous job with an immobilized wrist. All 533 patients were off work for at least one day.

In contrast, in our study $55 \%$ of the included patients performed manual work and $49 \%$ of the responders with a paid job resumed their jobs immediately with an immobilized wrist and therefore had no working days lost. This suggests that the most important factor influencing time off work among patients with immobilized wrists due to carpal injuries is the patient's occupation. In accordance with other authors, we concluded that non-manual workers had less time off work than manual workers [27].

The average total number of working days lost was lower in the active PEMF group compared to the placebo group. However, we could only retrieve information concerning the number of working days lost in $73 \%$ of the study population. In total, 49 out of 74 patients had no working days lost; 26 out of 39 patients in the active group compared to 23 out of 35 patients in the control group. Since $49 \%$ of the responders with a paid job was able to return to their previous job immediately, and only $11 \%$ was off work for more than one month, the costs due to productivity loss were less than we originally expected on basis of previously best available evidence from van der Molen et al. [2]. Moreover, this study was based on data from 1991 to 1993. Properties and demands regarding manual work have changed over this period of almost 20 years.

A number of patients were student or unemployed and therefore not generating a loss in working days in the context of a paid job. Although the difference in unemployed patients between groups was not statistically different $(p=0.27)$, we also calculated costs due to

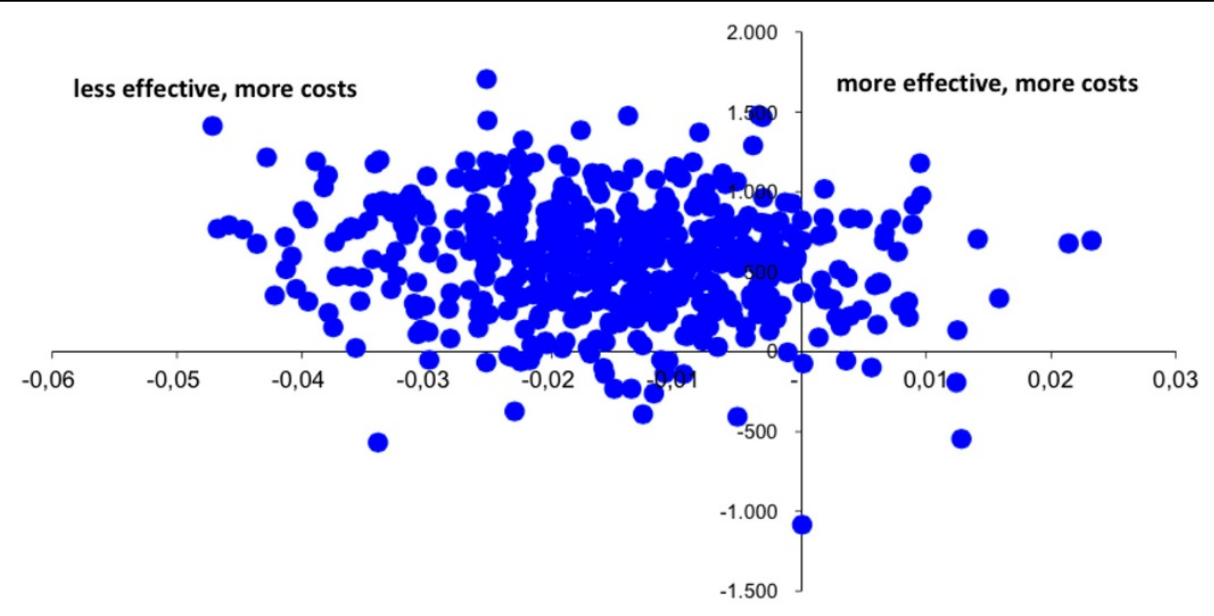

Figure 2 Cost-effectiveness plane for the incremental costs per QALY (based on EuroQol-5D). 
Table 9 Incremental cost-effectiveness ratio of PEMF vs. standard treatment for acute scaphoid fractures for working patients only

\begin{tabular}{llll}
\hline & Costs* $^{*}$ & QALY & ICER \\
\hline Group A (Active) & $€ 3305$ & 0.8474 & \\
Group B (Placebo) & $€ 2634$ & 0.8415 & \\
Increment & $€ 670$ & 0.0059 & 113559
\end{tabular}

${ }^{*}$ Costs are denoted in Euro.

QALY, quality adjusted life year; ICER, incremental cost-effectiveness ratio.

productivity loss and total costs among working patients only. Obviously, the number of working days lost was higher amongst working patients (15.32 days in the PEMF group vs. 18.83 days in the placebo group, $\mathrm{p}=$ 0.73 ) resulting in higher costs due to loss of productivity. However, mean total costs were still higher in the PEMF group. Combining the costs and effects for the subgroup of working patients resulted in an incremental costeffectiveness ratio of $€ 113559$ per QALY gained which is unlikely to be considered cost-effective given the commonly applied Dutch threshold value of $€ 40000$ [28].

Our research group performed the first CT-scan evaluated, double-blind, randomized, placebo-controlled trial to investigate the effect of PEMF bone growth stimulation on the time to union, functional outcome and costeffectiveness of acute fractures of the scaphoid. We found no conclusive evidence supporting the implementation of PEMF stimulation to the conservative treatment regime [15,29]. As reported in our recently published study concerning the clinical section of the study, the addition of PEMF stimulation to the conservative treatment of acute scaphoid fractures might accelerate union in a well-defined subgroup of stable undisplaced scaphoid waist fractures [15]. However, it does not improve overall functional and radiological outcomes of conservatively treated scaphoid fractures. These results are not consistent with the results of former acute fracture studies on the use of electrical bone growth stimulation. Heckman et al. reported in a randomized controlled trial concerning addition of LIPUS to the treatment protocol of acute diaphyseal tibia fractures, a significant decrease in time to union $(\mathrm{p}=0.0001)$ and substantial cost-savings [12]. Kristiansen et al. compared LIPUS with standard care in nonoperatively treated extra-articular distal radius fractures. The time to union was accelerated by 37 days $(\mathrm{p}<0.0001)$ and LIPUS treatment was associated with a significantly smaller loss of reduction $(\mathrm{p}<0.01)$ [14]. Mayr et al. reported on acute nondisplaced scaphoid fractures (Herbert B1 and B2) treated with LIPUS. Results showed a significant acceleration of the fracturehealing process by 17 days $(\mathrm{p}<0.01)$. Furthermore, there was significantly more trabecular bridging after six weeks in the LIPUS group $(81,2 \%)$ compared to the placebo group $(54,6 \%)$ [13].

A possible explanation for the difference in clinical outcome compared to previous literature and a limitation of our study may be the large heterogeneity of our study group, since we included different types of scaphoid fractures (Herbert types A1, A2, B1 and B2). Posthoc log-rank analysis of all data from our recently published clinical study revealed a significantly shorter time to union in the active PEMF group for undisplaced transverse scaphoid waist fractures (Herbert type A2 fractures) $[15,16]$. PEMF bone growth stimulation seems to have an accelerating effect on union in stable scaphoid waist fractures. Since unstable fractures are more likely to progress to nonunion, we think that stability of the fracture pattern may play a crucial role in predicting the effect of PEMF bone growth stimulation in scaphoid waist fractures. Therefore, electrical bone growth stimulation might be only effective in a well-defined subgroup of stable scaphoid fractures. Future studies should focus on this subgroup of scaphoid fractures to evaluate

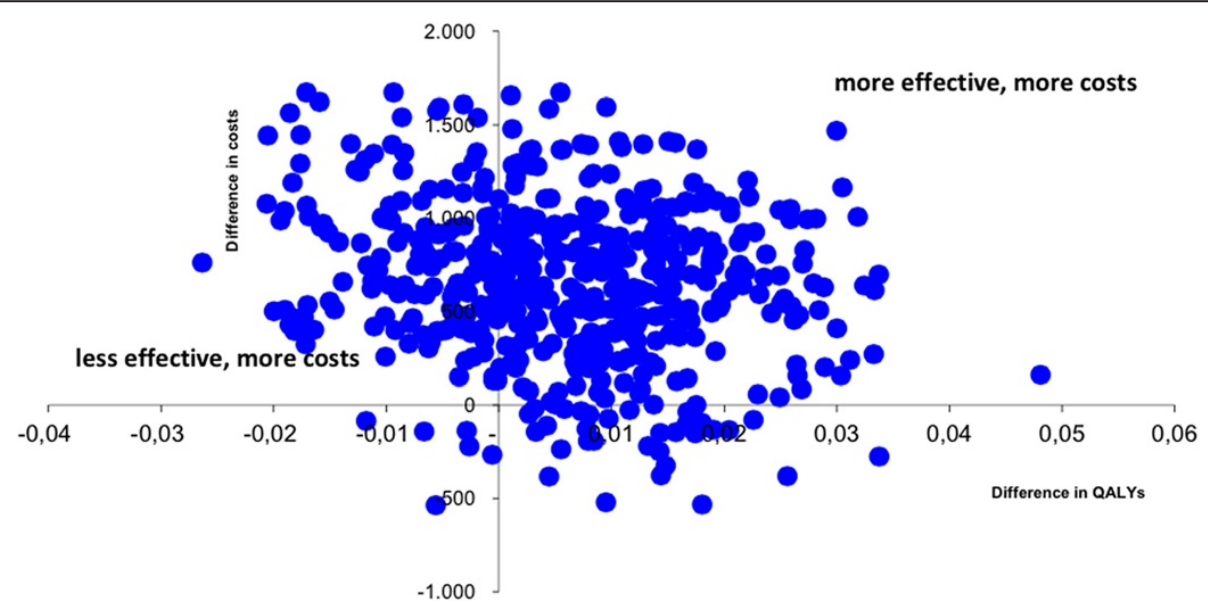

Figure 3 Cost-effectiveness plane for the incremental costs per QALY (based on EuroQol-5D) for working patients only. 


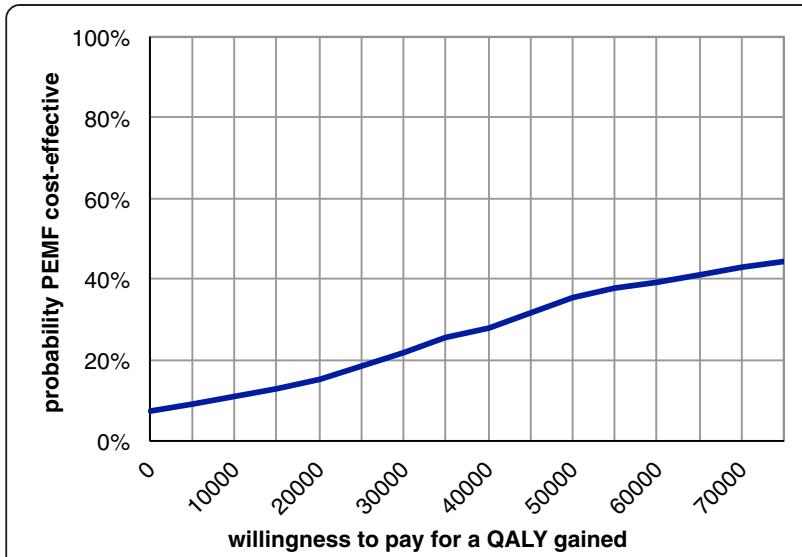

Figure 4 Cost-effectieveness acceptability curve (based on EuroQol-5D) for working patients only.

whether the use of PEMF is clinically effective and therefore justified among patients with this type of fracture. This seems particularly relevant since recent research has shown that the majority of scaphoid waist fractures are undisplaced [30].

Concerning the functional outcome as measured by the PRWHE questionnaire and general health related quality of life, as measured by the EuroQol-5D, we found no significant differences between the active PEMF group and the control group. Our cost-effectiveness analysis shows that PEMF stimulation significantly increases treatment costs against no significant improvement of general health related quality of life.

\section{Conclusions}

In conclusion, evidence from our clinical trial has not demonstrated sufficient advantage to warrant routine use of PEMF, although PEMF might accelerate union in a well-defined subgroup of stable, undisplaced scaphoid waist fractures. From a societal perspective, we conclude that the desired effects in terms of cost-effectiveness are not met. When comparing the effects of PEMF to placebo expressed in QALY's, PEMF cannot be considered a cost-effective treatment for acute fractures of the scaphoid bone in general.

\section{Abbreviations \\ PEMF: Pulsed electromagnetic fields; PRWHE: Patient rated wrist and hand evaluation; QALY: Quality adjusted life year; LIPUS: Low intensity pulsed ultrasound; VAS: Visual analogue scale; PRODISQ: PROductivity and DISease Questionnaire.}

\section{Competing interests}

The authors declare that they have no competing interests.

\section{Authors' contributions}

PFWH was applicant for the research grant and responsible for design of the study, patient recruitment in Maastricht University Medical Centre, acquisition, analysis and interpretation of all data, drafting and revision of the manuscript and is corresponding author. BABE performed the statistical and cost-utility analyses and was responsible for interpretation of all data and revision of the manuscript.
JPMS was responsible for analysis and interpretation of all data and drafting and revision of the manuscript. KD performed the acquisition, registration, analysis and interpretation of all data. MP recruited patients in Maastricht University Medical Centre, participated in the design of the study and performed statistical analysis of all data as well as revision of the manuscript. PRGB recruited patients in Maastricht University Medical Centre, coordinated the research project and participated in design of the study and revision of the manuscript. All authors read and approved the final manuscript.

\section{Acknowledgements}

We would like to thank M. van Wezenbeek, K.A. Kolkman, E.L.L. Twiss, C.H.J. Berghmans and P.A.M.G.M. Dirven for their significant contributions to this study.

This work was supported by a research grant from the Netherlands Organisation for Health Research and Development (ZonMW foundation, reference 171001004).

\section{Author details}

${ }^{1}$ Department of Surgery and Traumasurgery, Maastricht University Medical Centre, PO Box 5800, 6202 AZ Maastricht, The Netherlands. 'Department of Clinical Epidemiology \& Medical Technology Assessement (CEMTA), Maastricht University Medical Centre, PO Box 58006202 AZ Maastricht, The Netherlands.

Received: 15 May 2014 Accepted: 27 March 2015

Published online: 11 April 2015

\section{References}

1. Tiel-van Buul MM, van Beek EJ, Broekhuizen AH, Bakker AJ, Bos KE, van Royen EA. Radiography and scintigraphy of suspected scaphoid fracture. A long-term study in 160 patients. J Bone Joint Surg Br. 1993;75:61-5.

2. van der Molen AB, Groothoff JW, Visser GJ, Robinson PH, Eisma WH. Time off work due to scaphoid fractures and other carpal injuries in The Netherlands in the period 1990 to 1993. J Hand Surg Br. 1999;24:193-8.

3. Hove LM. Epidemiology of scaphoid fractures in Bergen, Norway. Scand J Plast Reconstr Surg Hand Surg. 1999:33:423-6.

4. Schaefer $M$, Siebert HR. [Fracture of the semilunar bone]. Unfallchirurg. 2002;105:540-52. quiz 552-543.

5. Duckworth AD, Buijze GA, Moran M, Gray A, Court-Brown CM, Ring D, et al. Predictors of fracture following suspected injury to the scaphoid. J Bone Joint Surg Br. 2012;94:961-8.

6. Divelbiss BJ, Adams BD. Electrical and ultrasound stimulation for scaphoid fractures. Hand Clin. 2001;17:697-701.

7. Raudasoja L, Rawlins M, Kallio P, Vasenius J. Conservative treatment of scaphoid fractures: a follow up study. Ann Chir Gynaecol. 1999:88:289-93.

8. Hannemann PF, Brouwers L, van der Zee D, Stadler A, Gottgens KW, Weijers $\mathrm{R}$, et al. Multiplanar reconstruction computed tomography for diagnosis of scaphoid waist fracture union: a prospective cohort analysis of accuracy and precision. Skeletal Radiol. 2013;42:1377-82.

9. Rajagopalan BM, Squire DS, Samuels LO. Results of Herbert-screw fixation with bone-grafting for the treatment of nonunion of the scaphoid. J Bone Joint Surg Am. 1999;81:48-52.

10. Mollon B, da Silva V, Busse JW, Einhorn TA, Bhandari M. Electrical stimulation for long-bone fracture-healing: a meta-analysis of randomized controlled trials. J Bone Joint Surg Am. 2008;90A:2322-30.

11. Otter MW, McLeod KJ, Rubin CT. Effects of electromagnetic fields in experimental fracture repair. Clin Orthop Relat Res. 1998;355:S90-S104.

12. Heckman JD, Ryaby JP, McCabe J, Frey JJ, Kilcoyne RF. Acceleration of tibial fracture-healing by non-invasive, low-intensity pulsed ultrasound. J Bone Joint Surg Am. 1994;76:26-34

13. Mayr E, Rudzki MM, Rudzki M, Borchardt B, Hausser H, Ruter A. [Does low intensity, pulsed ultrasound speed healing of scaphoid fractures?]. Handchir Mikrochir Plast Chir. 2000;32:115-22.

14. Kristiansen TK, Ryaby JP, McCabe J, Frey JJ, Roe LR. Accelerated healing of distal radial fractures with the use of specific, low-intensity ultrasound. A multicenter, prospective, randomized, double-blind, placebo-controlled study. J Bone Joint Surg Am. 1997;79:961-73.

15. Hannemann PF, van Wezenbeek MR, Kolkman KA, Twiss EL, Berghmans CH, Dirven PA, et al. CT scan-evaluated outcome of pulsed electromagnetic fields in the treatment of acute scaphoid fractures: a randomised, 
multicentre, double-blind, placebo-controlled trial. Bone Joint J. 2014;96-B:1070-6.

16. Herbert TJ, Fisher WE. Management of the fractured scaphoid using a new bone screw. J Bone Joint Surg Br. 1984;66:114-23.

17. Karle B, Mayer B, Kitzinger HB, Frohner S, Schmitt R, Krimmer H. [Scaphoid fractures-operative or conservative treatment? A CT-based classification]. Handchir Mikrochir Plast Chir. 2005;37:260-6.

18. Hannemann P, Gottgens KW, van Wely BJ, Kolkman KA, Werre AJ, Poeze M, et al. Pulsed Electromagnetic Fields in the treatment of fresh scaphoid fractures. A multicenter, prospective, double blind, placebo controlled, randomized trial. BMC Musculoskelet Disord. 2011;12:90.

19. MacDermid JC, Turgeon T, Richards RS, Beadle M, Roth JH. Patient rating of wrist pain and disability: a reliable and valid measurement tool. J Orthop Trauma. 1998;12:577-86,

20. Brooks RG, Jendteg S, Lindgren B, Persson U, Bjork S. EuroQol: health-related quality of life measurement. Results of the Swedish questionnaire exercise. Health Policy. 1991;18:37-48.

21. Hakkaart-van Roijen L, Tan S, Bouwmans C. Handleiding voor kostenonderzoek. Methoden en standaard kostprijzen voor economische evaluaties in de gezondheidszorg Geactualiseerde versie. 2010.

22. Koopmanschap MA. PRODISQ: a modular questionnaire on productivity and disease for economic evaluation studies. Expert Rev Pharmacoecon Outcomes Res. 2005;5:23-8.

23. Oostenbrink JB, Koopmanschap MA, Rutten FF. Standardisation of costs: the Dutch Manual for Costing in economic evaluations. Pharmacoeconomics. 2002:20:443-54.

24. Dolan P, Roberts J. Modelling valuations for EQ-5D health states - An alternative model using differences in valuations. Med Care. 2002:40:442-6.

25. Briggs $\mathrm{AH}$, Wonderling $\mathrm{DE}$, Mooney $\mathrm{CZ}$. Pulling cost-effectiveness analysis up by its bootstraps: A non-parametric approach to confidence interval estimation. Health Econ. 1997:6:327-40.

26. Efron B, Tibshirani RJ. An introduction to the bootstrap. CRC press. 1994.

27. Vinnars B, Ekenstam FA, Gerdin B. Comparison of direct and indirect costs of internal fixation and cast treatment in acute scaphoid fractures: a randomized trial involving 52 patients. Acta Orthop. 2007;78:672-9.

28. RVZ. Fair and sustainable care (Zicht op duurzame zorg). Council for Public Health and Health Care (The Hague). 2006

29. Hannemann PF, Gottgens KW, van Wely BJ, Kolkman KA, Werre AJ, Poeze M, et al. The clinical and radiological outcome of pulsed electromagnetic field treatment for acute scaphoid fractures: A randomised double-blind placebo-controlled multicentre trial. J Bone Joint Surg Br. 2012;94:1403-8.

30. Grewal R, Suh N, Macdermid JC. Use of computed tomography to predict union and time to union in acute scaphoid fractures treated nonoperatively. J Hand Surg Am. 2013:38:872-7.

\section{Submit your next manuscript to BioMed Central and take full advantage of:}

- Convenient online submission

- Thorough peer review

- No space constraints or color figure charges

- Immediate publication on acceptance

- Inclusion in PubMed, CAS, Scopus and Google Scholar

- Research which is freely available for redistribution 